TABLE IV - Number of patient-years of treatment necessary to prevent one stroke or one coronary event. Data from $M R C$ trials $^{\circ}$

\begin{tabular}{lcc}
\hline Drug treatment & $\begin{array}{c}\text { Younger patients } \\
\text { (mean age 52) }\end{array}$ & $\begin{array}{c}\text { Elderly patients } \\
\text { (mean age 70) }\end{array}$ \\
\hline & Stroke & \\
Treatment: & 566 & 286 \\
$\quad$ Diuretics & 1423 & 556 \\
$\beta$ Blockers & 833 & 370 \\
All treatments & Coronary event & \\
Treatment: & No benefit & 200 \\
Diuretics & No benefit & No benefit \\
$\beta$ Blockers & No benefit & 417 \\
All treatments & & \\
\hline
\end{tabular}

for older patients, but one trial has suggested that therapeutic benefit is maintained with increasing age, ${ }^{+}$ and consideration should be given to treating older patients with more severe hypertension, particularly if this is complicated by such conditions as heart failure or symptomatic ischaemic heart disease.

Treatment should always be started with low doses and doses increased only where indicated. For patients with uncomplicated hypertension the currently available evidence, particularly the MRC trial results, supports the choice of diuretics rather than $\beta$ blockers as first line treatment. The use of other therapeutic agents should be guided by the presence of coexisting disease. In individual patients, substitution of drugs is indicated when responses to initial treatment are poor or when adverse effects intercede. Combinations of drugs may be required in as many as $50 \%$ of patients, and they should be selected on the basis of complimentary modes of action.

We wish to acknowledge the support of our meetings by an educational grant from Bristol Myers Squibb.

1 Management Committee. Treatment of mild hypertension in the elderly. Med F Aust 1981;ii:398-402.

Amery A, Birkenhager WH, Brixko P, Bulpitt C, Clement D, Deruyttere M, $e t$ al. Mortality and morbidity results from the European working party on high blood pressure in the elderly trial. Lancet 1985;i:1349-54.

3 Coope J, Warrender TS. Randomised trial of treatment of hypertension in elderly patients in primary care. BMF 1986;293:1145-51.

4 SHEP Co-operative Research Group. Prevention of stroke by antihypertensive drug treatment in older persons with isolated systolic hypertension. fAMA drug treatment in

5 Dahlof B, Lindholm LH, Hanson L, Schersten B, Ekbom T, Wester P-O. Morbidity and mortality in the Swedish trial in old patients with hyper ension (STOP-Hypertension). Lancet 1991;338:1281-5.

6 Medical Research Council Working Party. MRC trial of treatment of hypertension in older adults: principal results. BMF 1992;304:405-12.

7 Petrie J, O'Brien E, Littler W, de Swiet M, Padfield P, Dillon M. Blood pressure measurement. 2nd ed. London: BMF, 1989.

8 Amery A, Birkenhager W, Brixko R, Bulpitt C, Clement D, Deruyttere M, et al. Efficacy of antihypertensive drug treatment according to age, sex, blood pressure, and previous cardiovascular disease in patients over the age of 60 . Lancet 1986;ii:589-92.

9 Amery A, Birkenhager W, Bulpitt C, Clement D, De Leeuw P, Dollery C, et al. Syst-Eur. A multicentre trial on the treatment of isolated systolic hypertension in the elderly: objectives, protocol and organisation. Aging 1991;3:287-302.

10 Potter JF, Beevers GD. Non-pharmacological reduction of blood pressure in the elderly. In: Amery A, Staessen J, eds. Handbook of hypertension. Vol 12. the elderly. In: Amery A, Staessen J, eds. Handbook of hypertensic

11 Staessen J, Van Hoof R, Fagard R, Amery A. Epidemiology of treated and untreated hypertension in the elderly. In: Amery A, Staessen J, eds. Handbook of hypertension. Vol 12. Hypertension in the elderly. Amsterdam: Elsevier, 1989:320-51.

12 Medical Research Council Working Party. MRC trial of treatment of mild hypertension: principal results. BMF 1985;291:97-104.

(Accepted 13 fanuary 1992)

\title{
Liver transplantation in 100 children: Cambridge and King's College Hospital series
}

Departments of Paediatrics and Surgery,

Addenbrooke's Hospital,

Cambridge

A Salt, FRACP, research fellow

G Noble-Jamieson, STATE

EXAM MED, research registrar

N D Barnes, FRCP, consultan

paediatrician

$\mathrm{K}$ Rolles, FRCS, lecturer in surgery

$\mathrm{N}$ Jamieson, FRCS, lecturer in surgery

P Johnston, FRACs, lecturer in surgery

$P$ Friend, FRCs, lecturer in surgery

R Y Calne, FRS, professor of surgery

King's College Hospital, London

A P Mowat, FRCP, professor in paediatric hepatology

Correspondence to: Dr N D Barnes, Department of Paediatrics,

Addenbrooke's Hospital,

Cambridge CB2 2QQ.

BMF 1992;304:416-21

A Salt, G Noble-Jamieson, N D Barnes, A P Mowat, K Rolles, N Jamieson, P Johnston, P Friend, R Y Calne

Abstract

Objective-To review the results of the Addenbrooke's and King's College Hospital children's liver transplantation programme.

Design-Retrospective analysis of the first 100 children to receive liver grafts at Addenbrooke's Hospital, Cambridge, from December 1983 to March 1990.

Setting-Addenbrooke's Hospital, Cambridge, and King's College Hospital, London.

Subjects - 153 children assessed for liver transplantation, of whom 22 died before a donor became available and 31 were considered unsuitable. 100 children received grafts, of whom 27 had second grafts.

Results-One year actuarial patient survival was $71 \%$, with $57 \%$ one year graft survival. In the last two years survival rates had improved considerably, with $86 \%$ of patients and $63 \%$ of grafts surviving for at least one year. Sixty five children were alive 12 to 86 months after transplantation; 63 were well and leading normal active lives and 56 had entirely normal liver function. Children's growth and development were essentially normal, with many showing remarkable catch up growth.

Conclusions - Liver transplantation offers children with terminal liver disease a high chance of a return to full quality life and normal development. Improved surgical and medical care have progressively improved survival. The timing of transplantation is critical but has been constrained particularly by the availability of donors and resources.
Introduction

The first successful orthotopic human liver transplantation was reported in 1967,' but the procedure has become widely accepted in the management of end stage liver disease only since $1983 .{ }^{2}$ In children, one year survival was less than $40 \%$ before $1980^{3}$ but has improved progressively, and good medium term results with normal growth, development, and quality of life have been achieved. ${ }^{45}$ The adult liver transplantation programme at Addenbrooke's and King's College Hospitals began in 1968, but a children's programme was not started until $1983,{ }^{6}$ when suitable donor organs began to become available after the benefits of the procedure were publicised on television. Of 349 liver transplants performed during December 1983 to March 1990, 127 were in 100 children under the age of 17 . We describe the outcome of these transplantations and discuss the reasons for improved survival over the past two years.

\section{Patients and methods}

During December 1983 to March 1990, 153 children were assessed for liver transplantation. Twenty two children died before a donor became available, and 31 were considered unsuitable for transplantation for reasons of tumour metastasis, parental refusal after discussion, or, before 1987, abnormal anatomy (such as absent inferior vena cava or blocked portal vein) or small size. One hundred children ( 40 boys and 60 girls) received grafts, three receiving combined liver and kidney grafts for oxalosis. Twenty seven received a 
second graft. The median age at the time of transplantation was 5.7 years, with a range from 3 months to 16 years. Thirty four children were less than 3 years old, and 37 weighed less than $12 \mathrm{~kg}$ when they received their transplant. Actuarial patient and graft survival were calculated as of the end of March 1991.

\section{ASSESSMENT}

Table I shows the diagnostic groups. Biliary atresia and hypoplasia, which we have considered as a single diagnostic category, was the commonest condition, with 51 children affected. Of the 43 children who had Kasai operations, only five were less than 8 weeks old, 21 were $8-11$ weeks old, and 15 were 12 weeks or older at the time of the procedure.

TABLE I - Diagnosis and outcome in children receiving liver transplants

\begin{tabular}{lcc}
\hline & \multicolumn{2}{c}{ Patients } \\
\cline { 2 - 3 } Diagnosis & $\begin{array}{c}\text { No receiving } \\
\text { transplant }\end{array}$ & $\begin{array}{c}\text { No (\%) } \\
\text { alive }\end{array}$ \\
\hline Biliary atresia and hypoplasia & 51 & $31(61)$ \\
$\alpha_{1}$ Antitrypsin deficiency & 17 & $12(71)$ \\
Acute hepatic failure & 6 & $3(50)$ \\
Chronic active hepatitis & 5 & $5(100)$ \\
Tyrosinosis & 4 & $3(75)$ \\
Budd-Chiari syndrome & 3 & $2(67)$ \\
Oxalosis & 3 & $3(100)$ \\
Cholestatic syndrome & 3 & $2(67)$ \\
Hepatocellular carcinoma & 2 & 0 \\
Inborn error of metabolism & 2 & $1(50)$ \\
Crigler-Najiar syndrome & 1 & 0 \\
Protoporphyria & 1 & $1(100)$ \\
Wilson's disease & 1 & $1(100)$ \\
Cryptogenic cirrhosis & 1 & $1(100)$ \\
\hline Total & 100 & $65(65)$ \\
\hline
\end{tabular}

The indications for transplantation were generally the effects of progressive liver failure: poor growth and nutrition, despite full dietary supplements; variceal haemorrhage uncontrolled by sclerotherapy; portal hypertension with intractable ascites; recurrent life threatening infections, especially cholangitis and peritonitis; deranged synthetic liver function with prolonged prothrombin time and hypoalbuminaemia; hyperbilirubinaemia with encephalopathy or the hepatorenal syndrome, or both. Four children with metabolic disease received liver grafts despite normal liver function, three of whom had oxalosis and one Crigler-Naijar disease. Four children with tyrosinaemia received transplants because of the risk of developing hepatocellular carcinoma.

Results of standard liver function tests before transplantation showed wide variation because of the different indications for transplantation. Serum bilirubin concentrations ranged from 6 to $1044 \mathrm{mmol} / \mathrm{l}$, with a median of $275 \mathrm{mmol} / \mathrm{l}$, and prothrombin time from 12 to 100 seconds with a median of 19 seconds. Ascites was present before 67 transplantations, bleeding from oesophageal varices before 30 , and encephalopathy before 15 first and nine second transplantations. Haemofiltration or dialysis was required before retransplantation in nine children.

The median waiting time for a transplant was 90 (range one to 300 ) days. Of the 22 children who died before a suitable donor could be found, 12 were less than two years old and weighed less than $12 \mathrm{~kg}$. Fifty three operations were considered emergencies (needed within $\mathbf{4 8}$ hours) or urgent (within two weeks). In the children with biliary atresia 25 out of 65 transplantations $(38 \%)$ were registered as urgent. In the past two years this had increased to 14 out of 19 operations (73\%).

\section{DONORS AND OPERATIONS}

Donors were matched for major blood group compatibility and approximately for size. Reduced liver grafts were used only in emergencies. Major blood group barriers were crossed on three occasions. Cytomegalovirus mismatching was avoided for non-urgent transplants.

The donor and recipient operations have been described. ${ }^{7}$ Various biliary tract anastomoses were used: gall bladder conduit to roux loop in 64 operations, conduit to common bile duct in $29,{ }^{8}$ common bile duct end to end in 16, and common bile duct to roux loop in 18. Thirteen children received reduced grafts with either the left or the right lobes or the left lateral segment; the techniques for reduced grafts have been recently described. ${ }^{910}$

\section{IMMUNOSUPPRESSION}

Intravenous azathioprine $(1.5 \mathrm{mg} / \mathrm{kg} / \mathrm{day})$ and prednisolone $(2 \mathrm{mg} / \mathrm{kg} / \mathrm{day})$ were given from the time of operation and cyclosporin $(4 \mathrm{mg} / \mathrm{kg} /$ day in two doses) from the second postoperative day or as soon as an adequate urine output was established. Oral cyclosporin $(10 \mathrm{mg} / \mathrm{kg} /$ day $)$ was started when the bile drainage tube was clamped. Trough whole blood cyclosporin concentrations were monitored with a selective monoclonal radioimmunoassay (Cyclotrak-Sp, Incstat, Minnesota, United States) and maintained between 100 and $200 \mu \mathrm{g} / \mathrm{l}$. If tolerated, triple therapy was maintained indefinitely, the prednisolone dosage being gradually reduced from day 14 to a maintenance dose of $2 \cdot 5 \cdot 5 \cdot 0 \mathrm{mg} /$ day either daily or on alternate days.

Acute rejection was suspected when there was one or more of fever, reduced bile flow, or deterioration in liver function in the absence of infection; vascular insufficiency; or biliary obstruction. In 1988 a Doppler ultrasound method of detecting reduced hepatic vein pulsatility, which reflects decreased hepatic compliance, was developed. This has proved a useful early indicator of acute rejection as reduced pulsatility often precedes any deterioration in biochemical liver function. ${ }^{11}$ Histological confirmation was obtained whenever possible. ${ }^{7}$ Children with significant rejection were treated with intravenous methylprednisolone $\left(500 \mathrm{mg} / \mathrm{m}^{2} /\right.$ day) for three days, and those with steroid resistant episodes were treated with antithymocyte immunoglobulin for 10 days.

\section{Infection prophylaxis}

Benzylpenicillin, tobramycin, and cefoxitin were given as prophylaxis for the first 48 hours. After October 1989 the regimen was changed to imipenem alone. From March 1989 cytomegalovirus hyperimmune globulin ${ }^{12}$ was given to recipients negative for cytomegalovirus antibodies who received a graft from a donor positive for the antibodies, and patients negative for antibody received blood that was also negative.

\section{Results}

The actuarial survival rate at one year was $71 \%$, falling to $64 \%$ at just over two years (fig). The survival

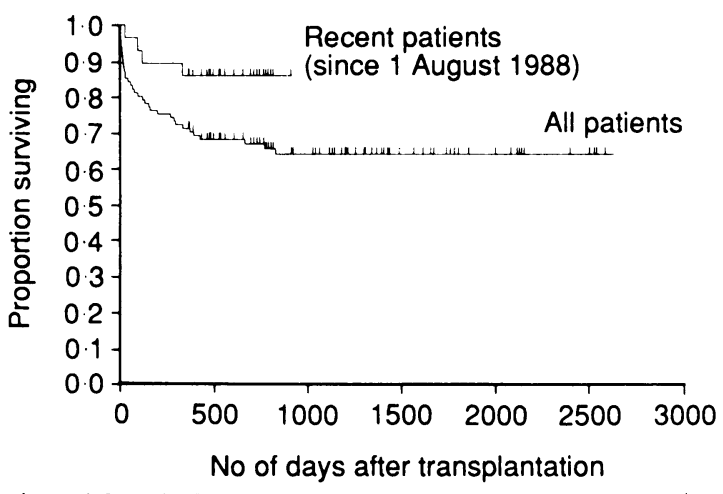

Actuarial survival in 100 children receiving liver transplants 
rate has considerably improved recently. From August 1988 one year actuarial survival rate was $86 \%$ with no late deaths, and children less than 3 years and under $12 \mathrm{~kg}$ also had a one year actuarial survival of $86 \%$ during this period compared with $63 \%$ in the whole series. Sixty five children were alive from 12 to 86 months after transplantation, with 50 surviving more than two years and 38 more than three years.

Sixty three children were well and leading normal active lives after transplantation. About half showed remarkable catch up growth, and half continued to grow at a normal rate. All had normal physical and intellectual development, except one child who had had grade four hepatic encephalopathy at transplantation. Seven children had abnormal liver function: five had chronic rejection, one had cytomegalovirus hepatitis, and one had recurrence of erythropoietic protoporphyria and cirrhosis. One child with chronic rejection was awaiting a second transplant.

One year actuarial graft survival was $57 \%$, and from August 1988 this improved to $63 \%$. Twenty seven grafts were replaced, 14 for ischaemia with infarction at three to 27 days and 13 for chronic rejection at four to 22 months. Ten second grafts were lost, resulting in the death of the child. Our use of reduction grafts only in emergencies is reflected in the low graft survival $(39 \%)$ for this procedure.

\section{CAUSES OF DEATH}

Thirty five children died after transplantation, 21 within 28 days of a first or second transplant operation, 10 within the next five months, and two within six to 12 months. Two children died after 24 and 26 months, one of metastatic hepatocellular carcinoma and the other with chronic rejection while awaiting a second transplant. One child died six months after receiving her second transplant, 22 months after the first. The cause of death was often multifactorial (table II).

Thirteen children died in hepatic failure, due to infarction of the graft in 12 and chronic rejection in one; many had multiorgan failure. Liver dysfunction was also present in 10 of 11 children who died with severe infection. In only two children did fatal infection follow increased immunosuppression for rejection. Poor hepatic function was the main predisposing factor to severe infection. Two children died from cerebral oedema and encephalopathy after retransplantation for hepatic failure. Severe intraoperative or postoperative haemorrhage, or both, also contributed to poor outcome, especially in the early years of the programme; two children with severe haemorrhage died soon after the operation. Respiratory failure was the primary cause of death in one child, who after retransplantation developed acute respiratory distress syndrome with associated infection and severe intraoperative bleeding.

Six children died of conditions unrelated to transplantation. Two died of encephalopathic processes; in one child the aetiology was unknown and the other, who received a transplant for valproate toxicity, was

TABLE II - Primary causes of death and main associated problems in children receiving liver transplants

\begin{tabular}{|c|c|c|c|c|c|}
\hline \multirow[b]{2}{*}{ Cause of death } & \multirow[b]{2}{*}{$\begin{array}{c}\text { No of } \\
\text { children }\end{array}$} & \multicolumn{4}{|c|}{ Main associations } \\
\hline & & Infection & $\begin{array}{c}\text { Liver } \\
\text { dysfunction }\end{array}$ & Haemorrhage & Renal failure \\
\hline Hepatic failure & 13 & 5 & 13 & 8 & 10 \\
\hline Bacterial infection & 9 & $2 \star$ & 8 & & 1 \\
\hline Viral infection & 2 & & 2 & & 1 \\
\hline Cardiac arrest & 2 & & 2 & 2 & \\
\hline Cerebral oedema & 2 & & 2 & 1 & 2 \\
\hline Respiratory failure & 1 & 1 & 1 & & \\
\hline \multicolumn{6}{|l|}{ Unrelated deaths: } \\
\hline Hepatocellular carcinoma & 3 & & & & \\
\hline Encephalopathy & 2 & & & & \\
\hline Cardiac surgery & 1 & & 1 & & \\
\hline Total & 35 & 8 & 29 & 11 & 14 \\
\hline
\end{tabular}

*Coincident viral infection.
TABLE III-Comparison of survival rates and complications after liver transplantation since August 1988 compared with the whole series

\begin{tabular}{|c|c|c|}
\hline & $\begin{array}{c}\text { Since } \\
\text { August } 1988\end{array}$ & $\begin{array}{c}\text { Since } \\
\text { December } 1983\end{array}$ \\
\hline \multicolumn{3}{|c|}{ Children } \\
\hline No of children & 28 & 100 \\
\hline \multicolumn{3}{|l|}{1 year actuarial patient survival: } \\
\hline All patients & $86 \%$ & $71 \%$ \\
\hline Patients weighing $<12 \mathrm{~kg}$ & $86 \%$ & $63 \%$ \\
\hline No (\%) having retransplantation & $10(36)$ & $27(27)$ \\
\hline \multicolumn{3}{|c|}{ Transplant courses } \\
\hline No of courses & 40 & 127 \\
\hline 1 year actuarial graft survival & $63 \%$ & $57 \%$ \\
\hline $\begin{array}{l}\text { No }(\%) \text { with urgent status at } \\
\text { transplantation }\end{array}$ & & \\
\hline $\begin{array}{l}\text { transplantation } \\
\text { No }(\%) \text { ventilated }<24 \text { hours }\end{array}$ & $\begin{array}{l}23(58) \\
14(35)\end{array}$ & $\begin{array}{l}53(42) \\
15(12)\end{array}$ \\
\hline No (\%) with graft infarction ${ }^{\star}$ & $6(15)$ & $28(22)$ \\
\hline Thrombotic infarction & $1(2 \cdot 5)$ & $14(11)$ \\
\hline Ischaemic infarction & $5(12)$ & $14(11)$ \\
\hline $\begin{array}{l}\text { No (\%) with haemorrhage (requiring } \\
\text { surgery) }\end{array}$ & $2(5)$ & $14(11)$ \\
\hline No (\%) with biliary complications & $5(13)$ & $38(30)$ \\
\hline \multicolumn{3}{|l|}{ Rejection: } \\
\hline No $(\%)$ acute & $37(93)$ & $81(64)$ \\
\hline No $(\%)$ chronic & $8(20)$ & $22(17)$ \\
\hline \multicolumn{3}{|l|}{ Infections (average No per course) } \\
\hline All & $73(1 \cdot 82)$ & $288(2 \cdot 27)$ \\
\hline Bacterial & $47(1 \cdot 17)$ & $212(1 \cdot 67)$ \\
\hline Viral & $8(0 \cdot 2)$ & $63(0 \cdot 49)$ \\
\hline Fungal & $18(0.45)$ & $36(0 \cdot 28)$ \\
\hline No $(\%)$ with convulsions & $13(33)$ & $29(23)$ \\
\hline No $(\%)$ with hypertension (treated) & $24(60)$ & $39(31)$ \\
\hline
\end{tabular}

^Infarction associated with or directly leading to graft loss or patient death.

found at necropsy to have Alpers's progressive neuronal degeneration. Three died with metastatic hepatocellular carcinoma, one of whom had a cardiomyopathy secondary to chemotherapy. One child with Alagille's syndrome, who also had chronic rejection, died during corrective surgery for Fallot's tetralogy. In all, six children died with normal liver function; in addition to the five children described above, one died of overwhelming haemophilus septicaemia six months after transplantation.

\section{POSTOPERATIVE PROBLEMS}

In those who survived to be discharged from hospital the median hospital stay was 45 (range 20-180) days. The median stay in intensive care was seven (range one to 80) days.

Vascular thrombosis and ischaemia leading to infarction of the graft occurred after 28 transplant operations (table III). It most commonly occurred between the third and seventh day (20 cases). Various strategies were used in an attempt to prevent this severe complication. Heparin by subcutaneous and intravenous routes proved of no value, but after low postoperative concentrations of natural anticoagulants were found ${ }^{13}$ from September 1987 antithrombin III replacement was given with the aim of maintaining levels between $80 \%$ and $120 \%$ until spontaneous recovery occurred. From August 1988 this was combined with low dose aspirin rectally $(2 \mathrm{mg} / \mathrm{kg}$ on alternate days). Since then the incidence of thrombotic infarction has fallen sharply, with only one instance in 40 transplant operations between August 1988 and March 1990.

Infarction occurred with all types of arterial anastomosis but was more common when it was necessary to use a conduit from a common iliac artery because no suitable recipient hepatic artery was present. This type of anastomosis was used in only six cases and failed partially or completely in all. Portal vein thrombosis, identified in seven children, was associated with a small $(3 \mathrm{~mm}$ or less) recipient or donor portal vein. Non-thrombotic infarction (with patent major hepatic arteries and portal vein) occurred as often as thrombotic infarction and seemed to represent a final common pathway for various forms of hepatic injury, including severe acute rejection, severe postoperative bleeding, and possibly preservation injury.

Acute rejection of sufficient severity to require treatment occurred at least once after 81 transplant 
operations. Twenty one children had two episodes of acute rejection, but only two had three or more. In the last two years more than $90 \%$ of all children who received transplants were shown to have acute rejection. This apparent increase was probably due to earlier and more frequent liver biopsy prompted by investigation with Doppler ultrasonography. There was a complete biochemical response to treatment after a three day course of high dose methylprednisolone in most children, but seven children with severe degrees of rejection in whom the clinical and histological features of acute rejection occurred after 60 days did not respond and later developed chronic rejection. Three children received ABO incompatible grafts in emergencies, but the grafts failed in all three because of severe rejection. Our standard immunosuppressive regimen has now been modified to include antithymocyte immunoglobulin.

Biliary tract complications occurred in 24 children. Nine children required surgical intervention for repair or reconstruction of the anastomosis. The complications resolved spontaneously in six children and after removal of the $T$ tube in a further six. Two children died and one developed chronic rejection before intervention. Fifteen children had either stenosis or obstruction of bile flow by the T tube or by biliary "sludge," and nine developed a biliary leak, seven with peritonitis or abscess formation, or both, and two with fistulae. Direct anastomosis of the common bile duct to a roux loop was associated with fewer complications than the other three types of anastomosis $6 \%(1 / 18)$ compared with $31 \%(5 / 16)$ for common bile duct end to end, $28 \%$ (18/64) for gall bladder conduit to roux loop, and $48 \%(14 / 29)$ for conduit to common bile duct.

Postoperative hypertension, sufficient to require antihypertensive drugs, occurred in 39 children (table III). Fourteen of these had $\alpha_{1}$ antitrypsin deficiency, and children with this deficiency had the highest incidence of severe hypertension (14/17, 82\%), probably because of associated renal disease. ${ }^{14}$ The apparent recent increase in the incidence of treated hypertension $(24 / 40,60 \%)$ was due to a policy of earlier and more active treatment of this complication.

Renal failure occurred in 18 children and was associated with hepatic failure in 14. Haemofiltration was used in 10 children; of these children, four who had severe hepatorenal syndrome and who survived to receive a second transplant, were maintained in a stable state for up to five days until another graft could be found. Haemodialysis was required in five children. Full recovery of renal function after successful retransplantation occurred between three and 30 days.

Various neurological complications were seen. Twenty nine children had fits: 10 were severely hypertensive; five had hepatic encephalopathy, one cytomegalovirus encephalitis, one cerebral ischaemia, and two pre-existing neurological abnormalities; in 10 children the cause was unclear. Only two children had high cyclosporin concentrations at the time of the seizure. Encephalopathy occurred in 27 children and was associated with hepatic failure in 22 and with hypertension or hypotension, hypoxia, status epilepticus, or cytomegalovirus encephalitis in the others. Seventeen (59\%) of the fits and $20(74 \%)$ encephalopathic episodes occurred in the first 14 days after transplantation. Only one child had long term sequelae.

Re-exploration was undertaken in 14 children who had postoperative blood loss greater than $90 \mathrm{ml} / \mathrm{kg}$, of whom only five survived. Recently operative blood loss has fallen, often to as low as $500-1000 \mathrm{ml}$.

Infection was the commonest complication and was the primary cause of death in 11 children. A total of 212 episodes of proved bacterial infection occurred after 95 transplants. The most common sites of infection were bile (77 episodes), blood (58), indwelling catheters (20), or wounds (25). Five children had hepatic abscesses and three abdominal abscesses; eight children had peritonitis, three with a biliary leak and three of the youngest (aged 7 to 11 months) with bowel perforation. The group D streptococcus was the most common organism isolated and accounted for $30 \%$ of positive blood cultures and biliary infections. Significant fungal infections occurred in 25 children; 21 infections were due to candida, three to aspergillus, and one to an unidentified yeast.

Viral infections were identified in 40 children; some children had more than one infection. Cytomegalovirus infection was the most common, occurring in 23 children; 13 had primary infections and nine of these children were known to have received an organ from a donor who was positive for cytomegalovirus antibody. Five of these children developed cytomegalovirus pneumonitis, seven hepatitis, and one child died of encephalitis coincident with pneumonitis and hepatitis. One child developed hepatitis after transfusion with blood positive for cytomegalovirus antibody. Nine children received treatment with ganciclovir for symptomatic disease, and eight recovered fully. Nine children had reactivated cytomegalovirus infection; although most had only mild symptoms, two developed hepatitis which recovered slowly but spontaneously. Four children who were negative for cytomegalovirus antibody and received a graft from a positive donor were treated prophylactically with cytomegalovirus hyperimmune gammaglobulin; this did not prevent symptomatic infection with the virus but may have reduced its severity.

Eight children contracted chickenpox and recovered fully after treatment with intravenous acyclovir. Other causes of viral infections were adenovirus strains (nine), Epstein-Barr virus (12), herpesvirus (nine), respiratory syncytial virus (one), and rotavirus (one). No lymphoproliferative disorders occurred.

\section{LATE COMPLICATIONS}

Late complications were defined as those occurring more than two months after transplantation. Fourteen children developed biliary stenosis, seven of whom required surgical correction. In two the stenosis was dilated successfully by the transhepatic percutaneous route. The most serious late complication was chronic rejection, which was recognised in 22 children from eight to 24 weeks after transplantation. Five died awaiting retransplantation; 12 received a second graft but five died later; one child was awaiting a second transplant; and four remained well. In three children with predominant bile duct loss but no arterial injury after severe prolonged acute rejection, liver function slowly improved; one of these children was treated with FK-506.

\section{Discussion}

The great improvement in patient and graft survival in our series over the past two years has occurred with improvements in surgical technique and medical management and also an increased rate of retransplantation. It cannot be explained by a shorter waiting time for transplantation or by selection of lower risk patients; $57 \%$ of the children were registered as requiring urgent (likely to die within two weeks) or emergency transplants, (likely to die within two days) (table III). Our recent results are similar to those reported in other series, which report one year actuarial survival rates of $76-88 \% .^{515} 16$

Biliary atresia is the commonest indication for transplantation in childhood. Early portoenterostomy is the preferred treatment but is usually too long delayed. Mieli-Vergani et al reported that portoenteros- 
tomy before eight weeks was successful in producing bile flow in $86 \%$ of cases $^{17}$ and Ohi et al achieved a 10 year survival rate of $73 \% .{ }^{18}$ When portoenterostomy fails most children die before the age of 2 years. ${ }^{17}$ In our series $88 \%$ of children had portoenterostomy at age 8 weeks or older $(37 \%$ aged $\geqslant 12$ weeks), indicating that transplantation could have been avoided in many if they had had earlier surgery. Small children, especially those with biliary atresia, present the greatest challenge to any paediatric liver transplantation programme, ${ }^{15}{ }^{16}$ and it is in these children that the greatest improvement in survival has occurred. Similar results have been reported from other centres, even in children under 1 year (one year actuarial survival $76-86 \%$ ), but at the cost of a higher retransplantation rate, ${ }^{16}$ which requires greater availability of small donors or greater use of graft reduction. ${ }^{515} 19$

\section{AVOIDING GRAFT INFARCTION}

Improved surgical techniques are likely to be responsible for the reductions in severe intraoperative and postoperative blood loss, thrombotic infarction of the graft, and biliary complications. Severe bleeding carries a poor prognosis with a high risk of graft infarction and respiratory or renal failure, or both. The formation of intra-abdominal blood clots can also cause compression of the graft and its major vessels. Other measures that may help to prevent infarction include the control of coagulation and acute rejection..$^{20}$ From late 1987 we measured concentrations of natural anticoagulants in all children and found them all to be in a hypercoagulable state after transplantation..$^{13}$ The decreased incidence of infarction over the final two years of the study was probably partly due to replacement of antithrombin III and reduction of platelet adhesiveness with low dose aspirin.

Acute rejection, which causes liver swelling and stiffness, also predisposes to graft infarction. Five of the six children who developed infarction of the graft in the past two years had preceding severe acute rejection. This experience was similar to that of Samuel et al, ${ }^{21}$ who reported on seven patients with graft infarction preceded by acute or chronic rejection. Increasing experience with Doppler ultrasound techniques ${ }^{11}$ allowed early diagnosis and treatment of acute rejection, possibly preventing infarction, and also prompt diagnosis of vascular thrombosis, which indicated the need for immediate surgical intervention or registration for urgent retransplantation. These improvements have led to an increase in the rate of retransplantation and improved survival (table III).

Acute rejection was common and was treated in $64 \%(81)$ of the survivors in this series. The incidence reported by some other groups was similar $(70-75 \%){ }^{52223}$ The more severe the acute rejection, the poorer the response to treatment and the eventual outcome. This experience was similar to that of McDonald et al. ${ }^{24}$ Late acute rejection (more than two months after transplant) was also more resistant to treatment. In contrast, mild early rejection was easily reversed.

\section{OTHER COMPLICATIONS}

Infection caused considerable morbidity. Primary infection with cytomegalovirus caused problems, most of which could have been avoided if it was possible always to use an organ from a donor negative for cytomegalovirus antibodies for a recipient who was antibody negative. ${ }^{25}$ However, mismatch was sometimes unavoidable, either because of the urgency of the transplantation or the shortage of donors. The risk of developing severe cytomegalovirus disease after receiving a mismatched transplant was greater than $80 \%$ according to Stratta $e t$ al,${ }^{26}$ and our experience was similar. The use of hyperimmune gammaglobulin ${ }^{12}$ did not completely prevent infection or disease, but no deaths from disseminated disease occurred after its use. ${ }^{27}$ Overt infection with cytomegalovirus was treated with ganciclovir, a drug which has proved effective and free from side effects in children ${ }^{28}$ and which we now use prophylactically after mismatched transplants. Two children with preoperative immunity to the virus developed cytomegalovirus hepatitis; both had received grafts positive for the virus antibodies and may have experienced reinfection with the donor strain. Contrary to previous belief, such patients are clearly at risk and should be closely observed for cytomegalovirus disease. A further risk factor for developing cytomegalovirus disease is the use of antilymphocytic antibodies for immunosuppression. ${ }^{29}$

The most serious late complication was chronic rejection, the incidence of which has remained constant. In some children it was preceded by resistant acute rejection, again emphasising the importance of either preventing or effectively treating acute rejection. The incidence of chronic rejection has been variable in reported series, ranging from only $6 \%{ }^{26}$ to over $20 \%{ }^{29}$ without clear explanation. The histological features of chronic obliterative arteriopathy and bile duct loss are widely accepted, so the differences are unlikely to be due to diagnostic variation alone. The pathogenesis is unknown, but a combination of immune injury during episodes of rejection and ischaemic injury seems likely. ${ }^{29}{ }^{30}$ We saw recovery of "chronic rejection" with predominant bile duct loss but no arterial injury after prolonged acute rejection in three children, one of whom was treated with FK-506. ${ }^{31}$ This has also been reported recently by the Birmingham group. ${ }^{32}$ Prevention of bile duct injury from acute rejection, and possibly viral infection, may help to reduce the incidence of this serious complication.

\section{IMPROVING SURVIVAL RATES}

The timing of transplantation is important. Clearly, transplantation should be performed before a child becomes critically ill with liver and associated multiorgan failure. We were constrained not only by lack of suitable donors but by the scarcity of resources, especially trained nurses and intensive care beds; during $1989,20 \%$ of suitable paediatric donor organs had to be refused because of inadequate intensive care space and staffing levels. This resulted not only in a high mortality $(16 \%)$ while awaiting transplantation but in worsening of the condition of the children on the waiting list. Fifteen children developed encephalopathy before their first transplant operation, and nine developed renal failure. Altogether, 53 children became severely ill and required urgent or emergency transplantation. Several deaths could probably have been avoided by earlier transplantation.

The formidable list of complications detailed above should not obscure the fact that most children survive transplantation and enjoy almost completely normal lives, showing normal growth and development, attending school, and taking part in all appropriate activities for their age. Catch up growth has been impressive, psychological disturbance remarkably slight and usually transient, and social and academic progress normal. Recent survival figures show that advances in surgical technique and postoperative management continue to improve the results of this complex and demanding procedure. Morbidity and mortality will no doubt be further reduced by better understanding of the mechanisms of acute and chronic rejection and graft ischaemia and infarction, combined with improved methods of early detection and more specific methods of treatment of these complications. The number of patients awaiting urgent and emergency transplants has unfortunately increased during the past two years, and this is unlikely to change unless 
the availability of donor organs, intensive care facilities, and staffing levels can be improved.

We thank our colleagues in anaesthetics, especially $\mathrm{Dr}$ Klinck; our pathologist, Dr D Wight; our radiologists; and the nursing staff of the paediatric unit. We also thank Mr B Allenstein, who developed the database system for this programme and greatly helped with the analysis of the data.

1 Starzl TE, Groth CG, Brettschneider L, Penn I, Fulginiti VA, Moon JB, et al Orthotopic homotransplantation of the human liver. Ann Surg 1968;168: 392-415.

2 Naional Instures of Heath Consensus Development. Conference satement liver transplantation-June 20-23. Hepatology 1984;4(suppl): 107-10.

3 Starzl TE, Koep LJ, Schroter GPJ, Halgrimson CG, Porter KA, Weil R. Liver replacement for pediatric patients. Pediatrics 1979;63:825-9.

4 Pett S, Pelham A, Tizard J, Barnes N, Mieli-Vergani G, Mowat AP, et al. Pediatric liver transplantation: Cambridge/King's series, December 1983 to August 1986. Transplant Proc 1987; 19:3256-60.

5 Kalayoglu M, Stratta RJ, Sollinger HW, Hoffman RM, D'Alessandro AM, Pirsch JD, et al. Liver transplantation in infants and children. $\mathcal{F}$ Pediatr Sur 1989;24:70-6.

6 Rolles K, Williams R, Neuberger J, Calne R. The Cambridge and King's College experience of liver transplantation 1968-1983. Hepatology 1984; 4(suppl 1):50-5.

7 Calne RY, ed. Liver transplantation-the Cambridge/King's College Hospital experience. 2nd ed. Orlando: Grune and Stratton, 1987.

8 Calne RY. A new technique for biliary drainage in orthotopic liver transplanta tion utilizing the gall bladder as a pedicle graft conduit between the dono and recipient common bile ducts. Ann Surg 1976;184:605-9.

9 Bismuth H, Houssin D. Reduced-sized orthotopic liver graft in hepatic transplantation in children. Surgery 1984;95:367-70.

10 Broelsch CE, Emond JC, Thistlethwaite JR, Rouch DA, Whitington PF, Lichtnr JL. Liver transplantation with reduced size donor organs. Transplantation 1988;45:519-23.

11 Coulden RA, Britton PD, Farman P, Noble-Jamieson G, Wight DGD. Preliminary report: hepatic vein Doppler in the early diagnosis of acute live transplant rejection. Lancet 1990;336:273-5.

2 Syndman DR, Werner BG, Heinze-Lacey B, Berardi VP, Tilney NL, Kirkman RL, et al. Use of cytomegalovirus immune globulin to preven cytomegalovirus disease in renal transplant recipients. $N$ Engl f Med 1987;317:1049-54.

13 Harper PL, Luddington RJ, Carrel RW, Barnes N, Edgar PF, Seaman MJ, et al. Protein $\mathrm{C}$ deficiency and portal thrombosis in liver transplantation in children. Lancet 1988 ;ii:924-7.

14 Noble-Jamieson G, Barnes ND, Thiru S, Mowat AP. Severe hypertension after liver transplantation in alpha-1-antitrypsin deficiency. Arch Dis Child 1990;65:1217-21.

15 Sokal EM, Veyckemans F, de Ville de Govet J, Moulin D, Van Hoorebeeck N,
Alberti D, et al. Liver transplantation in children less than 1 year of age. f Pediatr 1990;117:205-10.

16 Otte JB, de Ville de Goyet J, de Hemptinne B, Kestens PJ, Moulin D, Carlier $\mathrm{MA}$, et al. Liver transplantation in children: report of $2 \frac{1}{2}$ years' experience at the University of Louvain Medical School in Brussels. Transplant Proc 1987; 19:3289-302.

17 Mieli-Vergani G, Howard ER, Portmann B, Mowat AP. Late referral for biliary atresia-missed opportunities for effective surgery. Lancet 1989; 421-3.

18 Ohi R, Nio M, Chiba T, Endo N, Goto M, Ibrahim M. Long-term follow-up after surgery for patients with biliary atresia. $\mathcal{F}$ Pediatr Surg 1990;25:442-5.

19 De Hemptinne B, de Ville de Goyet J, Kestens PJ, Otte JB. Volume reduction of the liver graft before orthotopic transplantation: report of a clinical of the liver graft before orthotopic transplantation: $r$ repo

20 Mazzaferro V, Esquivel CO, Makowka L, Belle S, Kahn D, Koneru B, et al. Hepatic artery thrombosis after pediatric liver transplantation - a medical or Hepatic artery thrombosis after pediatric liver tran

21 Samuel D, Castaing D, Reynes M, Bismuth H. Portal and arterial thrombosi in liver transplantation: a frequent event in severe rejection. Transplant Proc 1989;21:2225-7.

22 Gartner JC, Zitelli BJ, Malatack JJ, Shaw BW, Iwatsuki S, Starzl TE Orthotopic liver transplantation in children: two year experience with 47 patients. Pediatrics 1984;74:140-

23 Andrews WS, Wanek E, Fyock B, Gray S, Benser M. Pediatric live transplantation: a 3-year experience. F Pediatr Surg 1989;24:77-82.

24 McDonald JA, Painter DM, Bell R, Gallagher ND, Sheil AGR, McCaughan GW. Human liver allograft rejection: severity, prognosis and response to treatment. Transplant Proc 1989;21:3792-3.

25 Salt A, Sutehall G, Sargaison M, Woodward C, Barnes ND, Calne RY, et al. Viral and toxoplasma gondii infections in children after liver transplantation. f Clin Pathol 1990;43:63-7.

26 Stratta RJ, Shaefer MS, Markin RS, Wood RP, Kennedy EM, Langnas AN et al. Clinical patterns of cytomegalovirus disease after liver transplantation. Arch Surg 1989;124:1443-9.

27 Weimar W, Metselaar HJ, Balk AH, Mochtar B, Rothbarth PhH, Jeekel J. Passive immunization to prevent cytomegalovirus disease after kidney and heart transplantation. Transplant Proc 1990;22:229-32.

28 Salmela K, Hoeckerstedt K, Lautenschlager I, Eklund B, Isoniemi H, Holmberg C, et al. Ganciclovir in the treatment of severe cytomegalovirus disease in liver transplant patients. Transplant Proc 1990;22:238-40.

29 Oguma S, Belle S, Starzl TE, Demetris AJ. A histometric analysis of chronically rejected human liver allografts: insights into the mechanisms of bile duct loss: direct immunologic and ischaemic factors. Hepatolog 1989;9:204-9.

30 Foegh ML. Chronic rejection-graft arteriosclerosis. Transplant Proc 1990;22: $119-22$

31 Starzl TR, Fung J, Venekataramman R, Todo S, Demetris AJ, Jain A. FK506 for liver, kidney and pancreas transplantation. Lancet 1989;ii:1000-4.

32 Hubscher SG, Buckles JAC, Elias E, McMaster P, Neuberger JM. Reversible vanishing bile duct syndrome after liver transplantation: report of six cases. Transplant Proc 1991;23:1415-6.

(Accepted 4 November 1991)
Joyce Green Hospital,

Dartford, Kent

Christine Hardy-

Thompson, MB, senior house

officer in psychiatry

Maudsley Hospital,

Denmark Hill, London SE5

Martin W Orrell, MRCPSYCH, senior registrar

Klaus Bergmann, MD,

consultant psychiatrist

Correspondence to: $\mathrm{Dr}$ Orrell.

$B M \mathcal{F} 1992 ; 304: 421-2$

\section{Evaluating a psychogeriatric domiciliary visit service: views of general practitioners}

\section{Christine Hardy-Thompson, Martin W Orrell, Klaus Bergmann}

The value of the domiciliary consultation service has recently been questioned ${ }^{\prime}$ in view of the increasing cost from $£ 10 \mathrm{~m}$ in 1983 to $£ 20 \mathrm{~m}$ in $1988^{23}$ despite a decrease in the use of the service. General practitioner fundholding will obviously exert an influence on the future use of domiciliary visits. A recent review of general practitioners' referrals showed how little is understood about the correct level of service. ${ }^{4}$ Nevertheless, domiciliary consultations are a major component of a modern psychogeriatric service and may be preferred for new referrals. To plan or evaluate services it is vital to know the needs of general practitioners; we therefore investigated general practitioners' views and use of psychogeriatric domiciliary consultations.

\section{Subjects, methods, and results}

To assess the requirements for a successful domiciliary visit we interviewed the two local psychogeriatric consultants and a random sample of $10(10 \%)$ local general practitioners. This pilot study was used to compile a questionnaire, which was sent to all 105 general practitioners in the same catchment area.
We received $85(81 \%)$ completed replies. In all, 70 general practitioners had initiated one or more psychogeriatric domiciliary visits in the previous six months but only 19 had attended any. Several general practitioners commented that vague or awkward timing of the consultation often made it difficult to attend. The table gives the factors that general practitioners considered important in their decision to request a domiciliary visit in preference to another type of assessment. Forty thought the visit would often result in inpatient admission but only four always expected an admission.

Number of general practitioners ( $n=85$ ) who rated various factors a "essential" or "very important" in influencing their decision to request a domiciliary visit

Factor $\quad \begin{gathered}\text { No of } \\ \text { general } \\ \text { practitioners }\end{gathered}$

Home circumstances influencing mental health or management

Patient's physical ill health

Patient's physical disability

Patient's interaction with family/cohabitee at home

To obtain a consultant's opinion

Because a domiciliary visit facilitates admission Pressure from relatives

Fifty six of the general practitioners said that they had usually seen the patient the same day as the request for a visit was made, 67 said that a psychogeriatric domiciliary visit service was very important to their work, and 59 were very satisfied with the present service. Both psychogeriatric consultants agreed that a proper assessment for dementia meant seeing the patient's home and an informant. They valued the 